\title{
Analysis of Mechanical Response for a Reinforced Bedded Rock Slope under Rainfall
}

\author{
Longqi Li $(\mathbb{D})^{1,2}$ Changlin Li, ${ }^{1,2}$ and Chuan $\mathrm{He}^{1,2}$ \\ ${ }^{1}$ State Key Laboratory of Geohazard Prevention and Geoenvironment Protection, Chengdu University of Technology, \\ Chengdu 610059, China \\ ${ }^{2}$ College of Environment and Civil Engineering, Chengdu University of Technology, Chengdu 610059, China
}

Correspondence should be addressed to Longqi Li; lilongqi1986@gmail.com

Received 27 June 2018; Accepted 2 June 2019; Published 13 June 2019

Academic Editor: Castorina S. Vieira

Copyright (c) 2019 Longqi Li et al. This is an open access article distributed under the Creative Commons Attribution License, which permits unrestricted use, distribution, and reproduction in any medium, provided the original work is properly cited.

This paper has the objective to reveal real-time responses at several locations in reinforced bedded rock slopes under different rainfall conditions. Four scaled model tests have been conducted by varying rainfall patterns and slope inclinations, while several sensors, including fiber Bragg grating (FBG) displacement sensors, pore pressure sensors, and miniature pressure gauges, were instrumented in layers to capture corresponding responses during and after rainfall. The results show that the the slide of a reinforced bedded rock slope has a locking section, and the ultimate displacement under long-term medium rainfall was about three times larger than that under short-term storm rainfall. Meanwhile, the short-term storm rainfall generated little influence on the deeper pore pressure for reinforced bedded rock slope. The pore pressure at the surface layer was initially larger and then smaller than that at the intermediate layer for the same slope. For the slope under long-term medium rainfall, the shift moment was at 11.5 hours after testing started, while for the slope under short-term storm rainfall, the shift moment was at 3.5 hours after testing started. The thrust pressure ascended with the rainfall persisting and descended a little after rainfall. The descending in thrust pressure was mainly due to the fact that the strength of slope mass recovered partially with water flowing out of the slope from the frontal portion and the slide tendency was weakened. These results can provide engineers with more acquaintance with response characteristics for these kinds of rock slope.

\section{Introduction}

Rainfall is recognized as one of the most significant influential factors for slope instability, especially for bedded rock slopes which are more prone to slide. It was reported that millions of living and economic losses were induced by continuous storm every year around the world. Meanwhile, the slope without reinforcement is testified to be unsafe under most circumstances [1-3]. Thus, engineers attempted to arrange various reinforcing measures to consolidate sliding slopes and potential sliding slopes. Among them, anchors and antislide pile are two kinds of common used geostructures to resist the slide thrust transferred from the upper instability slope body in a bedded rock slope. Generally speaking, bedded rock slopes with such reinforced measurements are considered to be stable at most status. However, some failure cases of reinforced slopes whose antislide structure was designed unreasonably or excessive aging, were still be seen from time to time $[4,5]$. It is of great importance to further obtain and analyze the mechanical response of the reinforced structure to promote the safety assessment of bedded rock slopes under rainfall.

In recent years, a large amount of research has been focused on mechanical responses of reinforced structures, such as anchors and antislide piles, during its construction or initial service stage. For instance, insite instrumentation on stress in piles and anchors during several construction stages of a cut slope was monitored, and the most critical stage was revealed [6]. Some scholars also analyzed 
surcharge and pullout capacity of anchors in cohesive sloping ground under undrain conditions $[7,8]$, and the capacity of the anchor decreases with an increase in slope angle. The small-scaled model test on a construction procedure of self-supported earth-retaining structure was performed and compared with the analytical solutions $[9,10]$. Meanwhile, by summarizing several problems existing in the design and calculation of antislide piles, Gali and di Prisco [11] proposed a simplified displacement-based numerical procedure, which was further extended by $\mathrm{Gu}$ et al. [12] using FEM modelling. At the same time, Won et al. [13] and Lirer [14] studied the coupled effects of piles and surrounding slope mass, achieving that the safety factor for the slope was less conservative for a coupled analysis than for an uncoupled analysis, thus representing a definitely larger safety factor when the piles were installed in the middle of the slopes and the pile heads were restrained. Lai et al. [15] also investigated slope seismic behavior with embedded antislide piles by a shaking table model test, clarifying acceleration response and dynamic stress distribution of piles during earthquake. Ou et al. [16] and Zhao et al. [17] aimed at behavior comparison of different pile types, revealing the deformation characteristic of h-type antislide pile by experiment and numerical simulation. The above research has given extraordinary insights into the antislide pile application in diverse engineering backgrounds. However, investigation of response in a reinforced bedded rock slope under rainfall is scarcely to be reported. Besides, there are also three major issues unsolved. The first one is how to identify the potential risk position in a reinforced bedded slope. The second one is that the response difference between reinforced slopes with different inclination is uncertain by engineers. The third one is that for the same kind of reinforced bedded rock slopes, internal response norm under different rainfall conditions is still unknown.

In this paper, four sets of model tests have been undertaken by considering the inclination and rainfall conditions for a bedded rock slope reinforced by anchors and antislide piles. Various sensors, including FBG displacement, pore pressure, and thrust pressure gauges, have been instrumented at different portion in the slope body. Responses during and after rainfall were monitored and analyzed graphically, and some early-warning suggestions were also given according to corresponding test results. These results can provide engineers with more acquaintance with response characteristics and highlight related reinforcement design essentials for these kinds of rock slope.

\section{Scheme for Scaled Slope Model Tests under Rainfall}

2.1. Model Test Configuration. The test model is generalized from a series of bedded rock slopes on the left side of Guizhou-Guangxi high-speed railway. The height of the slopes along the railway is about $68-90 \mathrm{~m}$ and was excavated with three grades at a ratio of $1: 1$ and a height of $10 \mathrm{~m}$ per grade in initial design. The insite core drilling results revealed three layers from lower to deeper portion existing in the above slopes: a strongly weathered sandstone layer of the medium Jurassic Shaximiao Group $\mathrm{J}_{1} \mathrm{~S}$ with a thickness of about $19 \mathrm{~m}$, a weak interlayer containing $\mathrm{Al}_{2} \mathrm{O}_{3}, \mathrm{CaO}$, and few $\mathrm{SiO}_{2}$ with a thickness of about $1 \mathrm{~m}$, and a medium weathered sandstone layer of the earlier Jurassic Bachu Group $\mathrm{J}_{2} \mathrm{~B}$ with a thickness of about $50 \mathrm{~m}$. This typical geostructure was very prone to slide by cutting the slope toe during route construction, which was testified by several slide accidents during rainy seasons at the adjacent zone. Thus, a lot of reinforced structures, including antislide piles and anchors, were designed to be installed later at some section along the route. The generalized typical profile of the prototype-reinforced bedded rock slope is shown in Figure 1.

The test chute was made of steel frame and glasses, with a size of $260 \mathrm{~cm}$ long, $70 \mathrm{~cm}$ wide, and $65 \mathrm{~cm}$ thick. An artificial superimposed-spray rainfall system was set over the test chute, which had a capacity of modelling a rainfall intensity ranging from 0.2 to $2.8 \mathrm{~mm} / \mathrm{min}$ by combining eight sets of atomizing nozzles. This system was testified to have an evenness index of $85 \%$, satisfying the common requirement larger than $80 \%$ [18]. Meanwhile, the geometric scaled ratio between prototype and model $C_{\mathrm{L}}$ was set as $55: 1$. In order to focus on the influence of gravity, the scaled ratio of specific weight $C_{\gamma}$ was chosen to be $1: 1$. According to dimensional analysis and the second similarity norm, the scale ratio of the displacement $C_{\mathrm{d}}$ and elastic modulus $C_{\mathrm{E}}$ can be both calculated as $55: 1$, while the permeability coefficient scale ratio $C_{\mathrm{k}}$ was deduced to be $7.4: 1$. Based on the above geological settings and experiment equipment, a generalized model was built with a size of $188 \mathrm{~cm}$ in length, $70 \mathrm{~cm}$ in width, and $60 \mathrm{~cm}$ in depth.

In order to model the rainfall infiltration through the joints into the slope deeper portion, rock block made of similarity materials, a mixture of quartz sand, barite powder, plaster, cement, and water, was used to construct the slope body. A lot of orthogonal experiments based on the above materials were conducted to determine the mass ratio of different rocks. The ultimate mass ratio of the strongly weathered sandstone was adopted to be quartz sand: barite powder : cement : plaster $:$ water $=38: 16: 0.8: 0.3: 16.5$. The mass ratio of the medium weathered sandstone was adopted to be quartz sand:barite powder:cement:plaster: water $=64: 20: 1: 0.5: 14.5$. The mass ratio of weak interlayer was adopted to be quartz sand:barite powder: plaster : clay $:$ water $=18: 45: 1.3: 2.1: 33.5$. The frame structure was manufactured in a special module with a mass ratio to be plaster : cement : urea resin $:$ water $=66: 28: 6: 60$, sharing the same mass ratio with the antislide pile model. The anchor was modeled by a steel rod with a diameter of $2 \mathrm{~mm}$ and a length of $30 \mathrm{~cm}$. The mechanical parameters of prototype and corresponding geomaterials in the slope body are listed in Table 1, while those of reinforced structures are listed in Table 2.

2.2. Monitoring System and Arrangement of Test Models. In order to monitor dynamic response in different kinds of slopes during model test, displacement, pore pressure, and thrust pressure sensors were installed in the test 


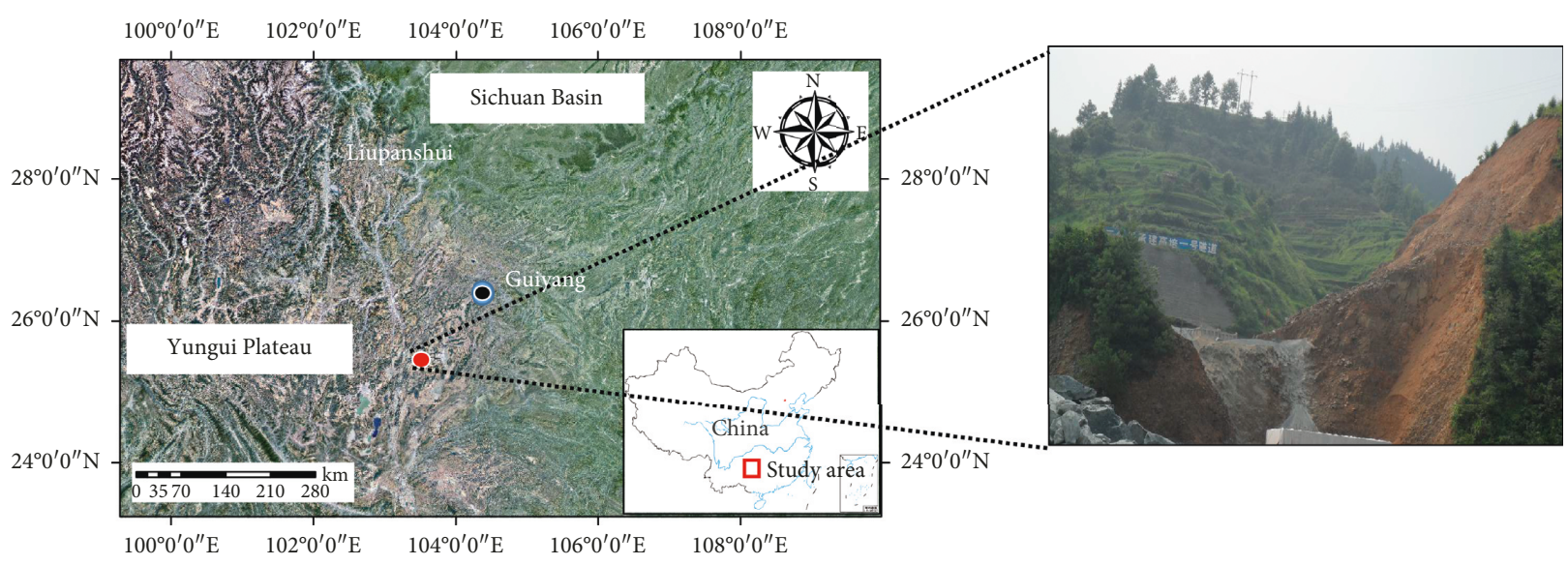

(a)

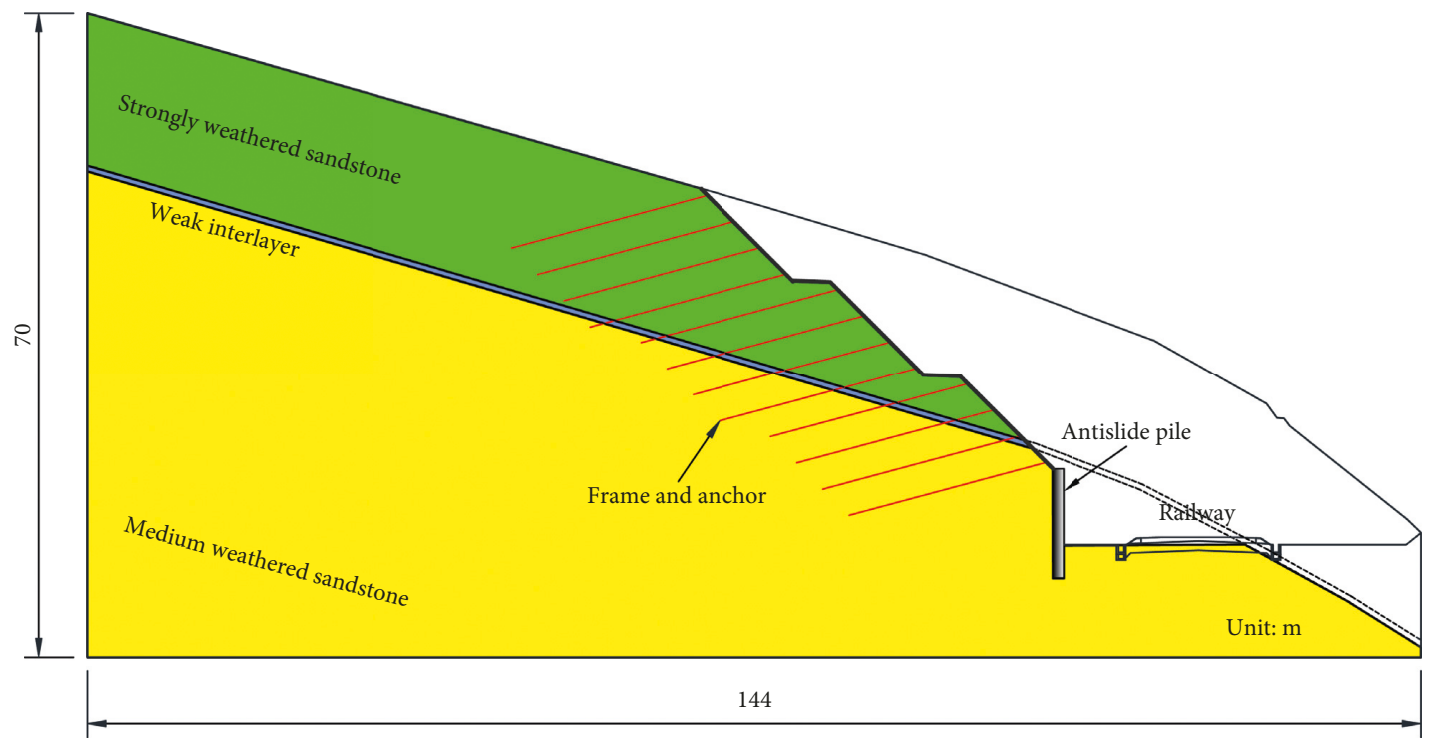

(b)

FIgURe 1: Profile of the bedded rock slope prototype.

TABLE 1: Mechanical parameters of prototype and model slope materials.

\begin{tabular}{lccccccc}
\hline \multicolumn{1}{c}{ Lithology } & & $\begin{array}{c}\text { Specific weight } \\
\gamma\left(\mathrm{kN} \cdot \mathrm{m}^{-3}\right)\end{array}$ & $\begin{array}{c}\text { Elastic modulus } \\
E(\mathrm{MPa})\end{array}$ & $\begin{array}{c}\text { Poisson's } \\
\text { ratio } \mu\end{array}$ & $\begin{array}{c}\text { Cohesion } \\
c(\mathrm{kPa})\end{array}$ & $\begin{array}{c}\text { Internal friction } \\
\text { angle } \varphi\left({ }^{\circ}\right)\end{array}$ & $\begin{array}{c}\text { Permeability } \\
\text { coefficient } k\left(\mathrm{~cm} \cdot \mathrm{s}^{-1}\right)\end{array}$ \\
\hline Strongly weathered & Prototype & 22.0 & 1600 & 0.19 & 300.0 & 35.0 & $7.08 \times 10^{-5}$ \\
sandstone & Model & 23.3 & 27.6 & 0.16 & 6.10 & 33.8 & $1.30 \times 10^{-5}$ \\
\hline Weak interlayer, joint & Prototype & 19.0 & - & 0.31 & 13.00 & 19.5 & $2.00 \times 10^{-3}$ \\
filling materials & Model & 18.8 & - & 0.26 & 0.25 & 17.4 & $9.50 \times 10^{-4}$ \\
\hline Medium weathered & Prototype & 24.0 & 7200 & 0.28 & 500.00 & 55.0 & $7.39 \times 10^{-6}$ \\
sandstone & Model & 24.8 & 118 & 0.21 & 8.50 & 49.2 & $3.10 \times 10^{-8}$ \\
\hline
\end{tabular}

TABLE 2: Reinforced structure mechanical parameters of prototype and model slope.

\begin{tabular}{lccccc}
\hline & Type & Specific weight $\gamma\left(\mathrm{kN} \cdot \mathrm{m}^{-3}\right)$ & Elastic modulus $E(\mathrm{GPa})$ & Poisson's ratio $\mu$ & Compression strength $\sigma(\mathrm{MPa})$ \\
\hline \multirow{2}{*}{ Frame } & Prototype & 25.0 & 234 & 0.25 & 0.18 \\
& Model & 23.6 & 3.8 & 0.18 & 0.35 \\
\hline \multirow{2}{*}{ Anchor } & Prototype & 78.0 & 212 & 0.11 & 470 \\
& Model & 76.0 & 26 & 0.25 & 133 \\
\hline \multirow{2}{*}{ Antislide pile } & Prototype & 25.0 & 23.4 & 0.19 & 133 \\
& Model & 24.2 & 0.37 & & 0.38 \\
\hline
\end{tabular}


model. Overall, there are three layers of sensors from surface to deeper layers. Among them, nine FBG displacement sensors with a resolution of $10^{-2} \mathrm{~mm}$ were set at three rows and three columns. A FBG displacement sensor consists of three portions: the first one is a hook in the slope mass which deforms with the surrounding materials, the second one is a steel wire connecting the hook with the tip of a beam, while the third one is a beam with a fiber Bragg grating on it. If the slope mass deforms, the hook at the same location will transfer this deformation to the tip of the beam by a steel wire. Then the fiber Bragg grating on the beam will capture it and translate it into variation in optical signal. A WOD-4 data acquisition was used to collect and store the displacement during experiment. Five pore pressure sensors with a resolution of $10^{-5} \mathrm{kPa}$ were fixed in the slope body with three of them at the intermediate layer to monitor the water variation near the weak interlayer. Three miniature pressure sensors with a resolution of $10^{-3} \mathrm{kPa}$ were also assigned behind the reinforcement structure to capture the thrust pressure at the frontal portion. These sensors were connected to a central monitoring system, which consisted of an acquisition unit, a demodulation unit, an analysis unit, and a storage unit. This system can realize completely autocontrol during the whole monitoring and analysis work. The arrangement of the overall test is shown in Figures 2 and 3, while some typical sensors are shown in Figure 4.

2.3. Model Test Program. The model slope test process should abide a strict norm to guarantee the reliability of final test results. In the present research, model rock blocks should be made through some special moulds at a steady temperature of $20^{\circ}$ and a humidity of $18 \%$ for 30 days, to get rid of the initial fissures formation in rock blocks. In contrast to rock blocks, the weak interlayer materials were made onsite during the slope model construction. A wooden framework was set in the front of the chute to maintain the model slope stable before formal model test begins. The slope body was stacked layer by layer from bottom to surface by rock blocks, cementing by some joint filling materials with an initial moisture content of $8 \%$. Meanwhile, different kinds of sensors were buried at designated locations with model slope construction, and sensor locations were marked on the side-wall of test chute ahead. It was noted that positions of sensors should be compacted to ensure closely contact between its stress surface and surrounding slope mass. When the chief slope body was finished, the assistant framework was moved away and the slope model was stationed overnight to achieve the slope model's initial stable status. Before monitoring starts, cables between sensors and monitoring system were checked again and fixed to avoid unfavorable disturbance. The rainfall data in Guizhou Province during the recent 30 years are shown in Table 3 . The corresponding rainfall pattern classification made by the local Bureau of Meteorology is shown in Table 4. Artificial rainfall was then applied according to the rainfall pattern. The long-term medium rainfall lasted for 14 hours with at an intensity of $1.2 \mathrm{~mm} / \mathrm{min}$, while the short-term storm rainfall lasted for 6 hours with at an intensity of $2.8 \mathrm{~mm} / \mathrm{min}$. It should be noted that the artificial rainfall device consisted of several nozzles, which can provide rainfall with a moist pattern. This setup can get rid of the exaggerated surface erosion at the slope existing in the past artificial rainfall devices. Moreover, all sensors were monitoring the real-time response for 20 hours to gain the physical variation during and after rainfall. A parallel model test was also carried out to verify the results for each formal model test. Furthermore, there were four sets of model tests altogether conducted in the present research considering alternation of the slope inclination and rainfall conditions, listed in Table 5.

\section{Test Results and Analysis}

3.1. Deformation Behavior. Figure 5 compares the displacement variation at frontal upper portion (monitored by D1, as shown in Figure 2) for four slope model tests. It can be seen that two phases, including an ascending section and a stable section, were existing in the displacement history. However, the displacement stopped ascending while rainfall ceased for two slopes under short-term storm rainfall. While under long-term medium rainfall, the displacement continued ascending after rainfall ceased. It suggested a lag phenomenon presented in displacement variation when undergoing long-term medium rainfall. This is because that long-term medium rainfall helped more rainfall water flow into the slope body, which weakened the strength of slope mass further after rainfall. Meanwhile, the displacement kept ascending for one hour after rainfall ceased for the slope with an inclination of $30^{\circ}$, while it kept ascending for three hours for the slope with an inclination of $50^{\circ}$. With slope inclination increasing, it would take more time for the displacement to reach stable status for reinforced slope. More attentions should be paid on the displacement variation for about three hours after rainfall ceased for steep reinforced slope. In addition, it can also be seen that the ultimate displacement under long-term medium rainfall was larger than that under short storm rainfall for the slope with same inclination. Taking the slope with an inclination of $50^{\circ}$ as the exam, the ultimate displacement was $6.1 \mathrm{~mm}$ under longperiod medium rainfall, while the value was $2.0 \mathrm{~mm}$ under short-period storm rainfall. The latter is about three times larger than the former.

Figure 6 depicts displacement variation along the transverse and depth direction, respectively, in slope with an inclination of $50^{\circ}$ under long-term medium rainfall. It can be seen from Figure 6(a) that the retral displacement was larger than the frontal one, which was relatively remarkable at the superficial layer. While at the deeper layer, the difference between different portions was very small. Meanwhile, at the superficial layer, disparity between two adjacent monitoring points also became larger with time persisting, especially after the test lasted for 13 hours. At the end of the model test, the displacement difference between the point D2 and D3 was $2.22 \mathrm{~mm}$, while that between the point D1 and D2 was 


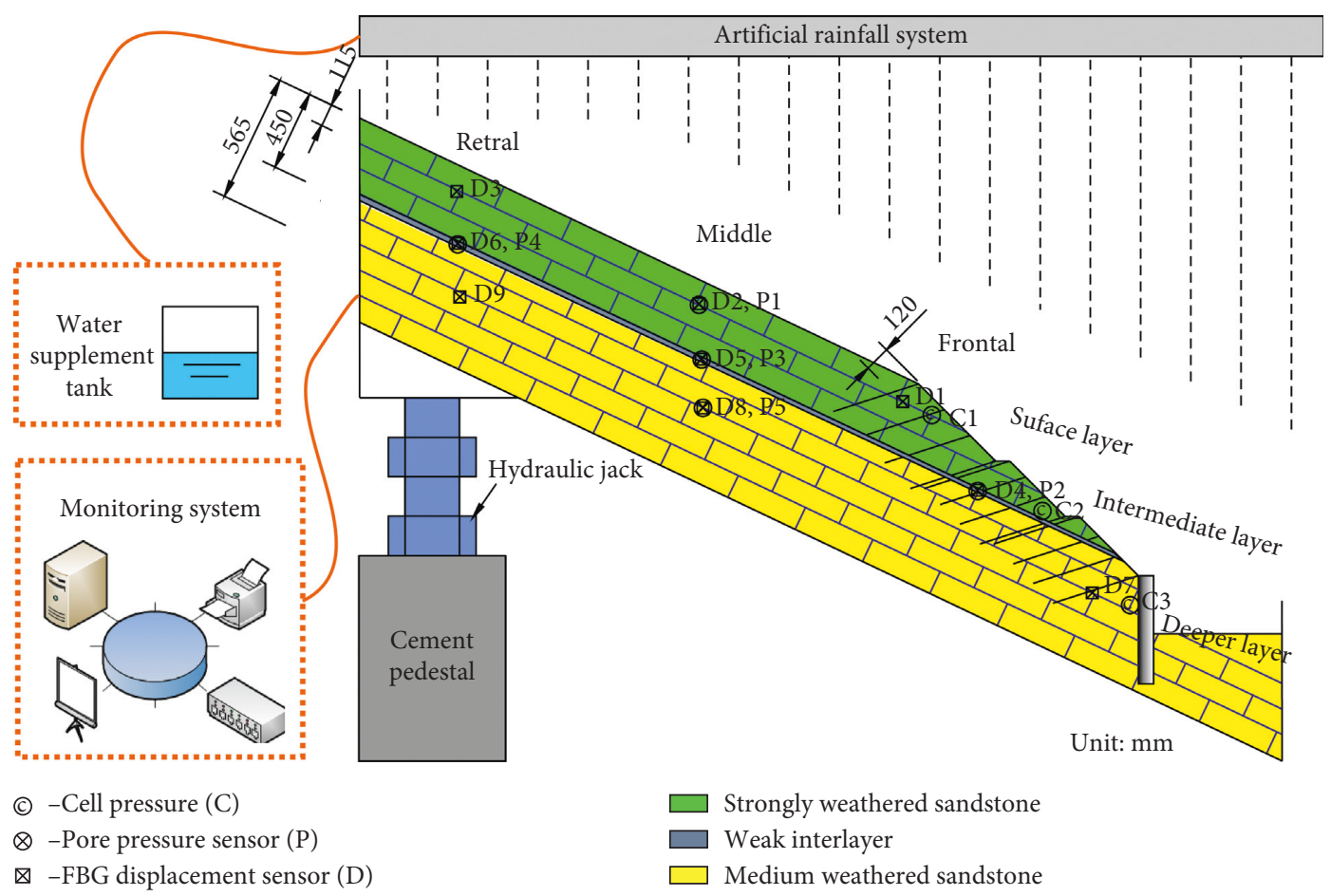

FIgURE 2: Sketch of the test model.

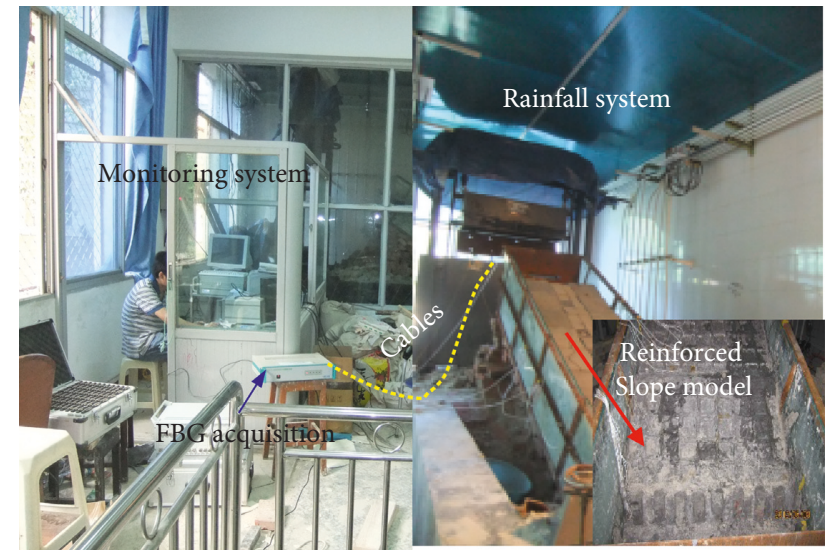

Figure 3: Arrangement of the test model.

only $0.85 \mathrm{~mm}$, which indicated that the displacement descended with distance decreasing from the reinforced structures. The deformation pattern of reinforced bedded rock slope turn an advancing type, which was different from that of the unreinforced slope whose deformation variation mainly shows a retrogressive type according to our previous studies [19]. Besides, it can be seen that the displacement above point D5 ascended notably during the test, while displacement at the deeper portion D8 did not ascend largely based on Figure 6(b). In spite of this, unlike point D2, displacement of point D5 shows a variation of three stages: an initial gradual stage before test duration reaching 8 hours, a fast ascending stage between 8 and 18 hours, and a stable stage after test duration exceeding 18 hours. It seemed that the variation of displacement in the intermediate layer was more complex than other portion. In fact, there existed a weak interlayer in that corresponding portion, which shows a sophisticated mechanical behavior than other portions when absorbing surrounding water.

3.2. Pore Pressure Response. Figure 7 illustrates the pore pressure along the depth direction for different rainfall conditions and inclinations. As shown in Figure 7(a), the pore pressure in the surface layer ascended as rainfall started for slope under different rainfall conditions, while at the deeper layer, like point P5, the pore pressure was not so sensitive. The deeper pore pressure began ascending after rainfall lasting for 6 hours for slope under long-term medium rainfall, while it remained little change during whole test period under short-term storm rainfall. It suggested that short-term storm rainfall generated little influence on the deeper pore pressure for reinforced bedded rock slope. Nonetheless, it can be seen that the displacement still ascends a little from Figure 6(a), which may be induced by the increase of specific weight of upper slope body through wetting of rainfall water. In the meantime, the pore pressure at the surface layer was initially larger and later smaller than that at the medium layer for the same slope. For the slope under long-term medium rainfall, the shift moment was at 11.5 hours after test started, while for the under short-term storm rainfall, the shift moment was at 3.5 hours after test started. Another interesting issue was a small vibration phenomenon appearing in the pore pressure of surface layer of slope under long-term medium rainfall (M2). This is because displacement in this layer changed rapidly, which induced rock blocks to push each other and bring forth partial excess pore pressure in the corresponding zone. 


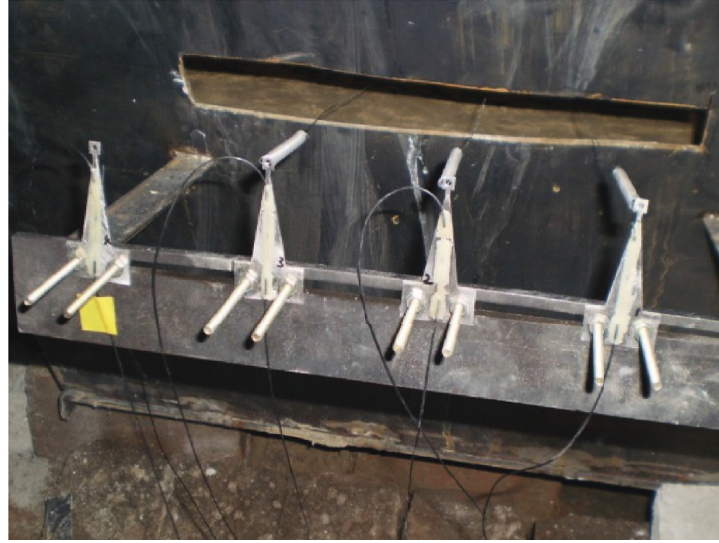

(a)

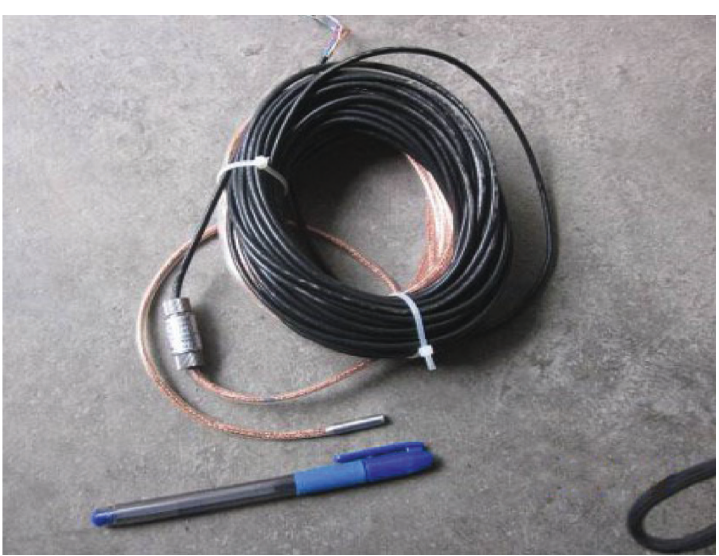

(b)

Figure 4: Some typical sensors: (a) the FBG displacement sensor; (b) the pore pressure sensor.

Table 3: Rainfall data in Guizhou Province during recent 30 years.

\begin{tabular}{|c|c|c|c|c|c|c|}
\hline Years & $1981-1985$ & $1985-1990$ & $1991-1995$ & $1996-2000$ & $2001-2005$ & $2006-2010$ \\
\hline Average annual rainfall days & 165 & 158 & 172 & 144 & 177 & 181 \\
\hline Average annual rainfall $(\mathrm{mm})$ & 2113.9 & 2074.7 & 1949.3 & 2044.9 & 2155.8 & 2388.1 \\
\hline Extremely transient rainfall intensity $(\mathrm{mm} / \mathrm{min})$ & 22 & 18 & 19 & 21 & 29 & 24 \\
\hline Extremely 24 -hour rainfall $(\mathrm{mm})$ & 286 & 332 & 368 & 337 & 389 & 344 \\
\hline
\end{tabular}

TABLE 4: Rainfall intensity classification in this test.

\begin{tabular}{lcccc}
\hline Type & $\begin{array}{c}\text { 24-hour accumulation rainfall } \\
\text { in real word }(\mathrm{mm})\end{array}$ & $\begin{array}{c}\text { Average rainfall intensity } \\
\text { in real word }(\mathrm{mm} / \mathrm{min})\end{array}$ & $\begin{array}{c}\text { Rainfall intensity in } \\
\text { model test }(\mathrm{mm} / \mathrm{min})\end{array}$ & $\begin{array}{c}\text { Equivalent rainfall intensity } \\
\text { in real word }(\mathrm{mm} / \mathrm{min})\end{array}$ \\
\hline Small & {$[0,30)$} & {$[0,5)$} & 1.2 & 8.88 \\
Medium & {$[30,90)$} & {$[5,10)$} & & 2.8 \\
Heavy & {$[90,120)$} & {$[10,15)$} & 20.72 \\
Storm & {$[120,+\infty)$} & {$[15,+\infty)$} & & 2 \\
\hline
\end{tabular}

Note: the condition of 24-hour accumulation rainfall in real word is not rigid at any occasion.

TABLE 5: Summary of model test sets and related factors.

\begin{tabular}{lccc}
\hline & & \multicolumn{2}{c}{$\begin{array}{c}\text { Inclination } \\
\beta\left({ }^{\circ}\right)\end{array}$} \\
& & 30 & 50 \\
\hline \multirow{2}{*}{ Rainfall type } & Long-term medium rainfall & M1 & M2 \\
& Short-term storm rainfall & M3 & M4 \\
\hline
\end{tabular}

The influence of slope inclination on the pore pressure under the same rainfall condition is illustrated in Figure $7(\mathrm{~b})$. The pore pressure in slope with an inclination of $50^{\circ}$ was larger than that with an inclination of $50^{\circ}$ in the same monitoring point. That is due to the fact that the displacement of the former slope was larger than the latter slope and more cracks forming in the former slope which allows more rainfall water flowing into the slope body. Meanwhile, in the deeper layer point P5, the initial pore pressure moment started at one hour after rainfall stopped, which suggested that water flowing was relative slow in the slope with an inclination of $30^{\circ}$ and water flowing from the

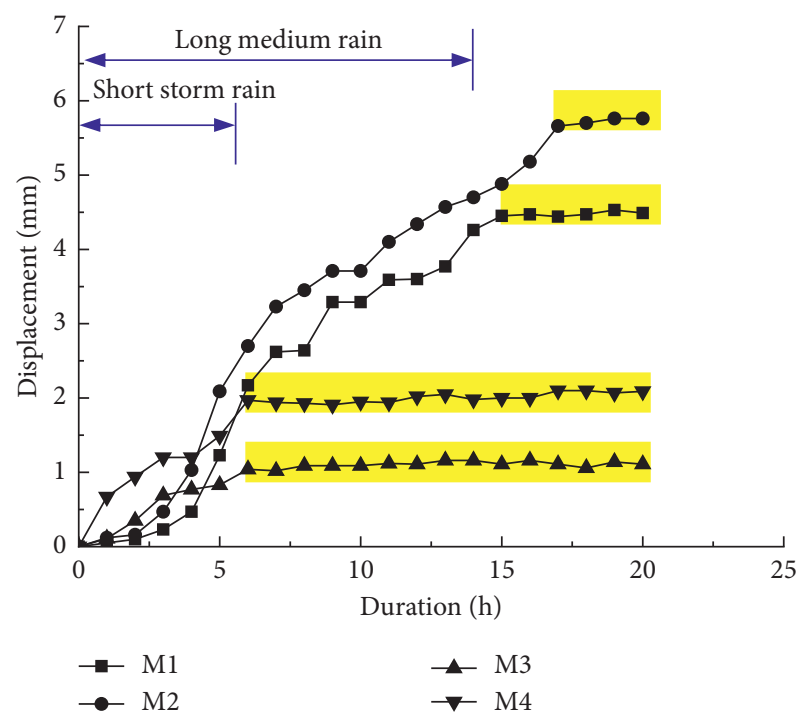

FIGURE 5: Displacement history at D1 point for four model slopes. The yellow zone is the stable phase. 


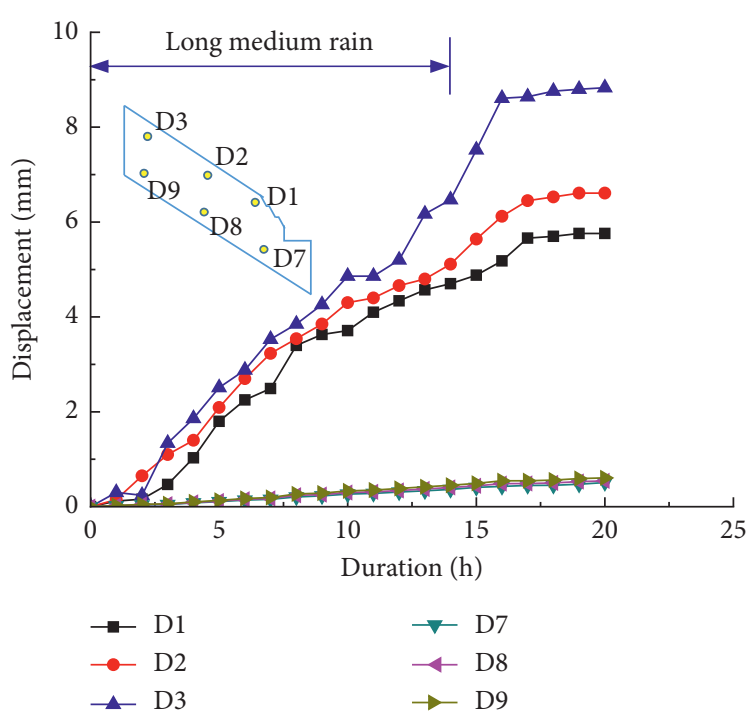

(a)

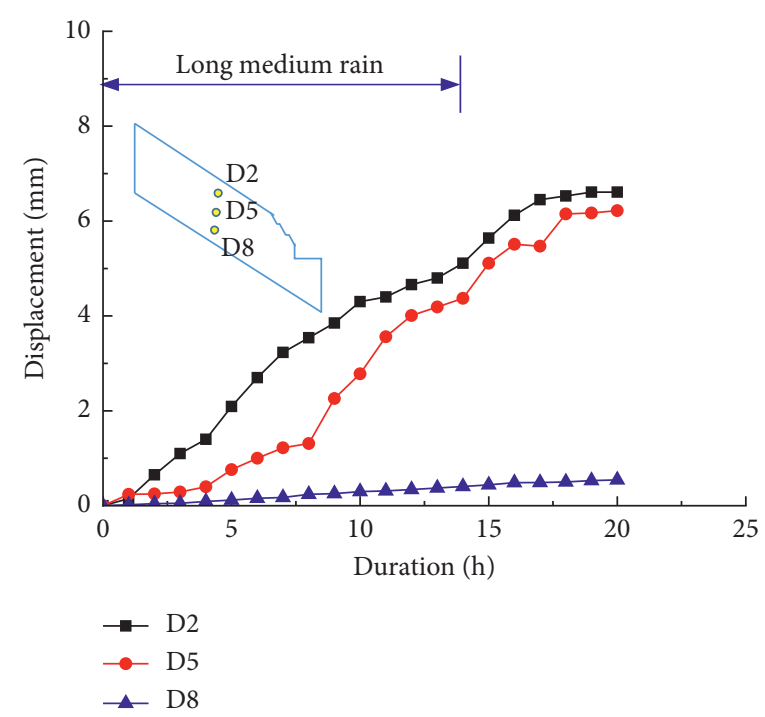

(b)

FIGURE 6: Displacement history in M2 slope along the (a) transverse direction and (b) depth direction.

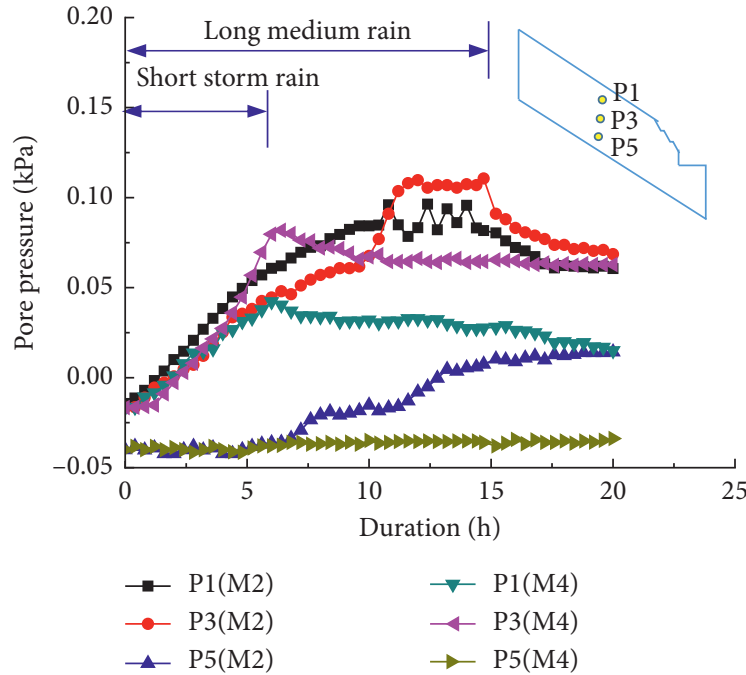

(a)

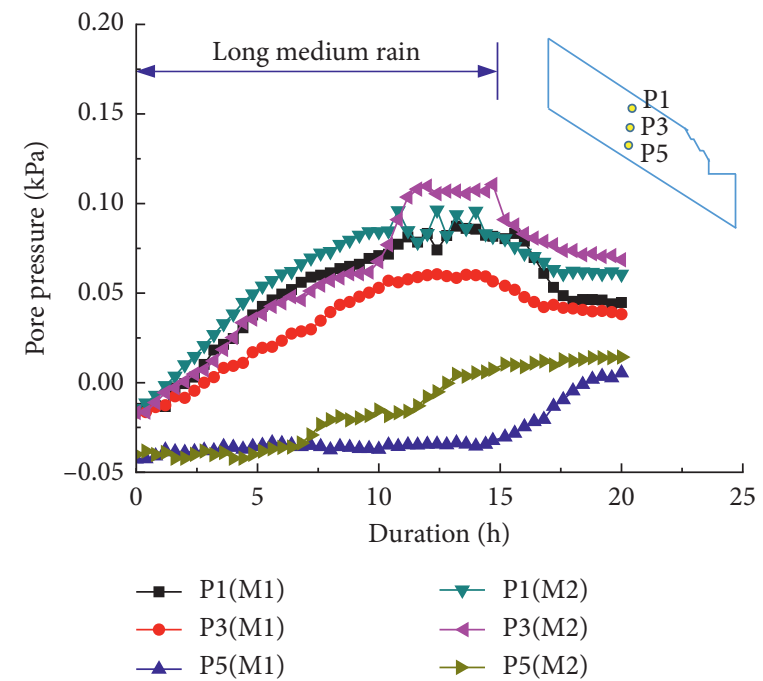

(b)

FIGURE 7: Comparison of pore pressure along the depth direction: (a) slope inclined at $50^{\circ}$ under different rainfall conditions; (b) slope inclined differently under the same long-term medium rainfall.

medium layer to deeper layer was still continuing after rainfall. If monitoring in site, it is suggested pore pressure after rainfall at the deeper layer should be monitored and analyzed carefully for slope under long-term medium rainfall.

\subsection{Thrust Stress Response on Reinforcement Structures.} Figure 8(a) compares thrust pressure on the reinforced structure at point $\mathrm{C} 3$ for different slope models. It can be seen that the largest thrust pressure exists in the slope M2 and the smallest thrust pressure exists in the slope M4. This suggested that the larger the slope inclined, the larger thrust pressure appeared on the reinforced structure. Meanwhile, the ultimate thrust pressure difference between slope inclined $50^{\circ}$ and $30^{\circ}$ was $2.66 \mathrm{kPa}$ under the long-term medium rainfall, and its difference value was $0.65 \mathrm{kPa}$ under the short-term storm rainfall. The former was about 4 times larger than the latter. It seemed that the rainfall conditions also affected the thrust pressure, which was more obvious when long-term medium rainfall occurred.

Thrust pressure at different locations in one slope is also analyzed in Figure 8(b). The thrust pressure ascended with the rainfall persisting and descended a little after rainfall. The descending in thrust pressure was mainly due to the fact that the strength of slope mass recovered partially with water 


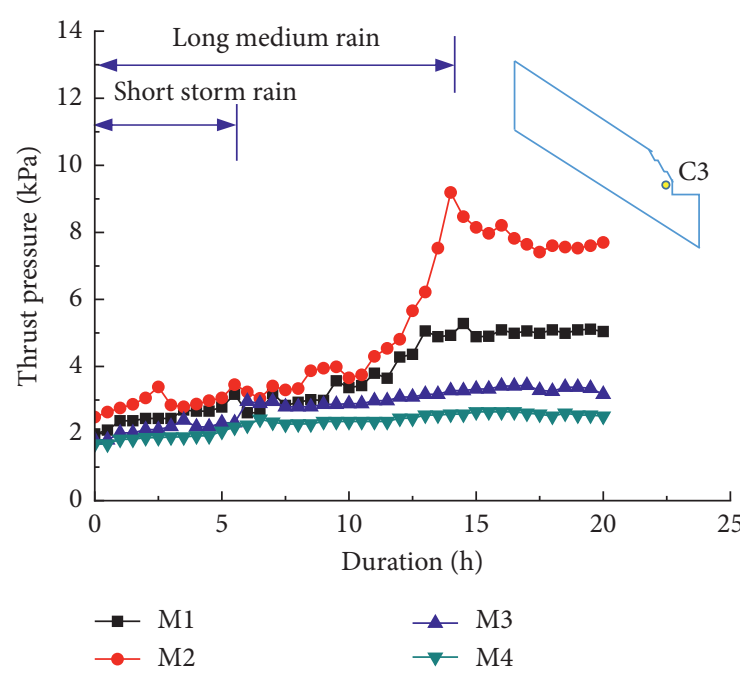

(a)

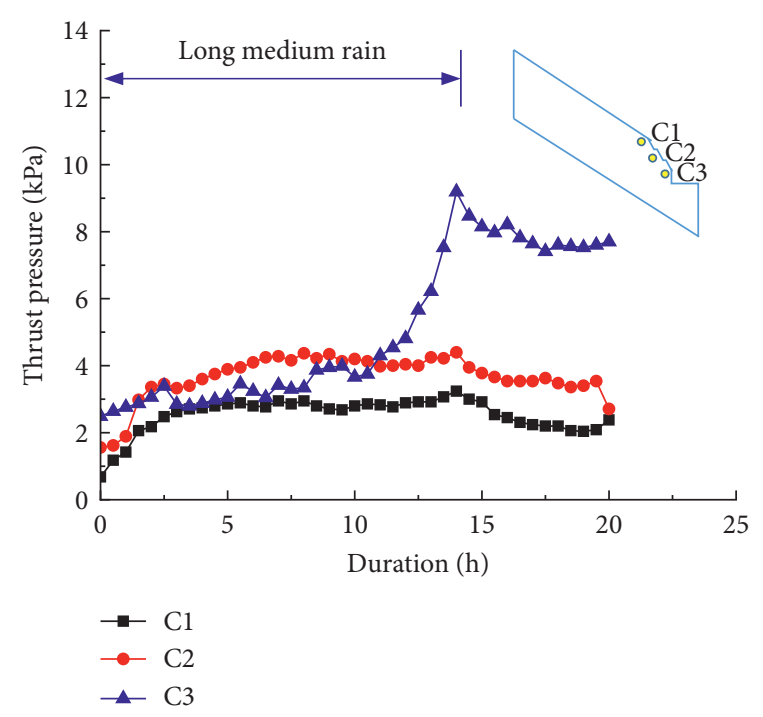

(b)

Figure 8: Thrust pressure on the reinforced structures: (a) thrust at point C3 for different slope models; (b) thrust at different locations for slope M2.

flowing out of the slope from the frontal portion and the slide tendency was weakened. Simultaneously, the thrust pressure in the surface layer had the largest ascending velocity at the initial phase, and then the largest ascending section changed to the point $\mathrm{C} 2$, and after 12 hours continuous rainfall, this section changed to the point $\mathrm{C} 3$. It reflected the bearing capacity exerting from the upper to the lower of the reinforced structure, and the antislide pile took the major responsibility to maintain stability of the bedded rock slope under rainfall.

\section{Conclusions}

Four model tests on mechanical behavior of reinforced bedded rock slopes under rainfall were conducted and analyzed in this paper. The variation norm of displacement, pore pressure, and thrust pressure on the reinforced structure was monitored. The following conclusions can be drawn:

(1) The displacement stopped ascending while rainfall ceased for two slopes under short storm rainfall. While under long-term medium rainfall, the displacement continued ascending after rainfall ceased. The ultimate displacement under long-period medium rainfall is about three times larger than that under short-term storm rainfall.

(2) The deformation pattern of reinforced bedded rock slope turn an advancing type, which was different from that of the unreinforced slope whose deformation variation mainly shows a retrogressive type.

(3) The short-term storm rainfall generated little influence on the deeper pore pressure for reinforced bedded rock slope. Meanwhile, the pore pressure at the surface layer was initially larger and later smaller than that at the medium layer for the same slope. For the slope under long-term medium rainfall, the shift moment was at 11.5 hours after test started, while for the under short-term storm rainfall, the shift moment was at 3.5 hours after test started.

(4) The thrust pressure ascended with the rainfall persisting and descended a little after rainfall. The descending in thrust pressure was mainly due to the fact that the strength of slope mass recovered partially with water flowing out of the slope from the frontal portion and the slide tendency was weakened.

\section{Data Availability}

The data in Figures 1-8 used to support the findings of this study are also included within the supplementary information files. Readers can also email to lilongqi1986@ gmail.com to ask for the original data in this paper.

\section{Conflicts of Interest}

The authors declare that they have no conflicts of interest.

\section{Acknowledgments}

The present study was financially supported by the National Natural Science Foundation of China (nos. 41502299 and 41372306) as well as Research Planning of Sichuan Education Department, China (no. 16ZB0105), State Key Laboratory of Geohazard Prevention and Geoenvironment Protection Independent Research Project (SKLGP2016Z007 and SKLGP2018Z017), Chengdu University of Technology Young and Middle Aged Backbone Program (Grant no. KYGG201720), and Sichuan Provincial Science and 
Technology Department Program (Grant no. 19YYJC2087). Financial support from the China Scholarship Council is also well appreciated.

\section{Supplementary Materials}

In the supplementary files, Figures 1-8 also appeared in the manuscript. Herein, independent files with a .tif manner are also given to make the figures more clear and easy-compiled. An independent file "1.displacement.xls" includes the original data of Figures 5, 6(a), and 6(b). An independent file "2.pore pressure.xls" includes the original data of Figures 7(a) and 7(b). An independent file "3.thrust pressure.xls" includes the original data of Figures 8(a) and 8(b). (Supplementary Materials)

\section{References}

[1] Z. He and B. Wang, "Instability process model test for bedding rock slope with weak interlayer under different rainfall conditions," Advances in Civil Engineering, vol. 2018, Article ID 8201031, 8 pages, 2018.

[2] C. Qi, J. Qi, L. Li, and J. Liu, "Stability analysis method for rock slope with an irregular shear plane based on interface model," Advances in Civil Engineering, vol. 2018, Article ID 8190908, 8 pages, 2018.

[3] Y. Chen, P. Wu, Q. Yu, and G. Xu, "Effects of freezing and thawing cycle on mechanical properties and stability of soft rock slope," Advances in Materials Science and Engineering, vol. 2017, Article ID 3173659, 10 pages, 2017.

[4] F. Silva, T. W. Lambe, and M. W. Allen Marr, "Probability and risk of slope failure," Journal of Geotechnical and Geoenvironmental Engineering, vol. 134, no. 12, pp. 1691-1699, 2008.

[5] Z.-P. Deng, D.-Q. Li, X.-H. Qi, Z.-J. Cao, and K.-K. Phoon, "Reliability evaluation of slope considering geological uncertainty and inherent variability of soil parameters," Computers and Geotechnics, vol. 92, pp. 121-131, 2017.

[6] G.-C. Kang, Y.-S. Song, and T.-H. Kim, "Behavior and stability of a large-scale cut slope considering reinforcement stages," Landslides, vol. 6, no. 3, pp. 263-272, 2009.

[7] S. K. Shukla, S. Khandelwal, V. N. Verma, and N. Sivakugan, "Effect of surcharge on the stability of anchored rock slope with water filled tension crack under seismic loading condition," Geotechnical and Geological Engineering, vol. 27, no. 4, pp. 529-538, 2009.

[8] B. Paramita, "Pullout capacity of strip plate anchor in cohesive sloping ground under undrained condition," Computers and Geotechnics, vol. 78, pp. 134-143, 2016.

[9] Q. Luo, L. Li, and L. H. Zhao, "Quasi-static analysis of seismic stability of anchored rock slope under surcharge and water pressure conditions," Rock and Soil Mechanics, vol. 11, pp. 101-106, 2010, in Chinese.

[10] C. Kim, J. Kwon, J.-C. Im, and S. Hwang, "A method for analyzing the self-supported earth-retaining structure using stabilizing piles," Marine Georesources \& Geotechnology, vol. 30, no. 4, pp. 313-332, 2012.

[11] A. Galli and C. di Prisco, "Displacement-based design procedure for slope-stabilizing piles," Canadian Geotechnical Journal, vol. 50, no. 1, pp. 41-53, 2013.

[12] X. J. Gu, T. Q. Zhou, and S. L. Lu, "Stability analysis on antislide pile to reinforce slope based on ABAQUS," Applied Mechanics and Materials, vol. 580-583, pp. 711-714, 2014.
[13] J. Won, K. You, S. Jeong, and S. Kim, "Coupled effects in stability analysis of pile-slope systems," Computers and Geotechnics, vol. 32, no. 4, pp. 304-315, 2005.

[14] S. Lirer, "Landslide stabilizing piles: experimental evidences and numerical interpretation," Engineering Geology, vol. 149150, pp. 70-77, 2012.

[15] J. Lai, Y. Zheng, Y. Liu, H. W. Liu, and Y. Lee, "Analysis of shaking table model test on embedded anti-slide piles under earthquake," Electronic Journal of Geotechnical Engineering, vol. 19, pp. 3963-3976, 2014.

[16] X. D. Ou, Y. C. Tang, W. Cui, J. Q. Li, and X. Pan, "Model test and numerical simulation of h-shaped anti-sliding pile," Chinese Journal of Rock Mechanical Engineering, vol. 39, no. 1, pp. 1936-1943, 2012, in Chinese.

[17] B. Zhao, Y. S. Wang, Y. Wang, T. Shen, and Y. C. Zhai, "Retaining mechanism and structural characteristics of h type anti-slide pile (hTP pile) and experience with its engineering application," Engineering Geology, vol. 222, pp. 229-37, 2017.

[18] L. Q. Li, S. X. Luo, W. K. Wei et al., "Model tests of rainfall infiltration effect on bedded rock slope with weak interlayer," Chinese Journal of Rock Mechanics and Engineering, vol. 32, no. 9, pp. 1772-1778, 2013, in Chinese.

[19] L.-Q. Li and N.-P. Ju, "Effect of the inclined weak interlayers on the rainfall response of a bedded rock slope," Journal of Mountain Science, vol. 13, no. 9, pp. 1663-1674, 2016. 


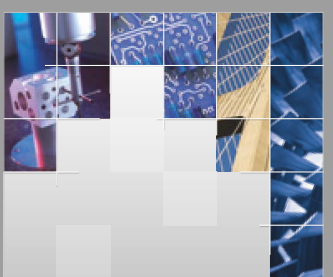

\section{Enfincering}
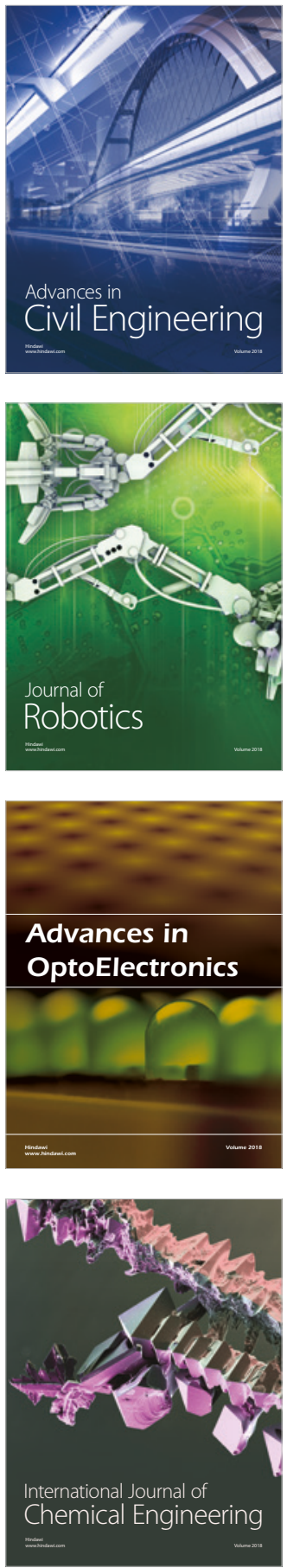

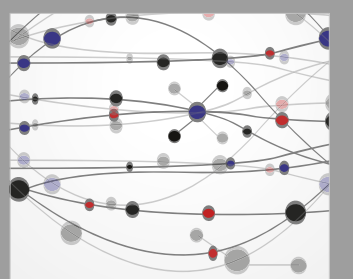

\section{Rotating \\ Machinery}

The Scientific World Journal

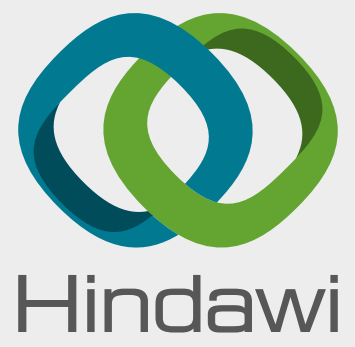

Submit your manuscripts at

www.hindawi.com
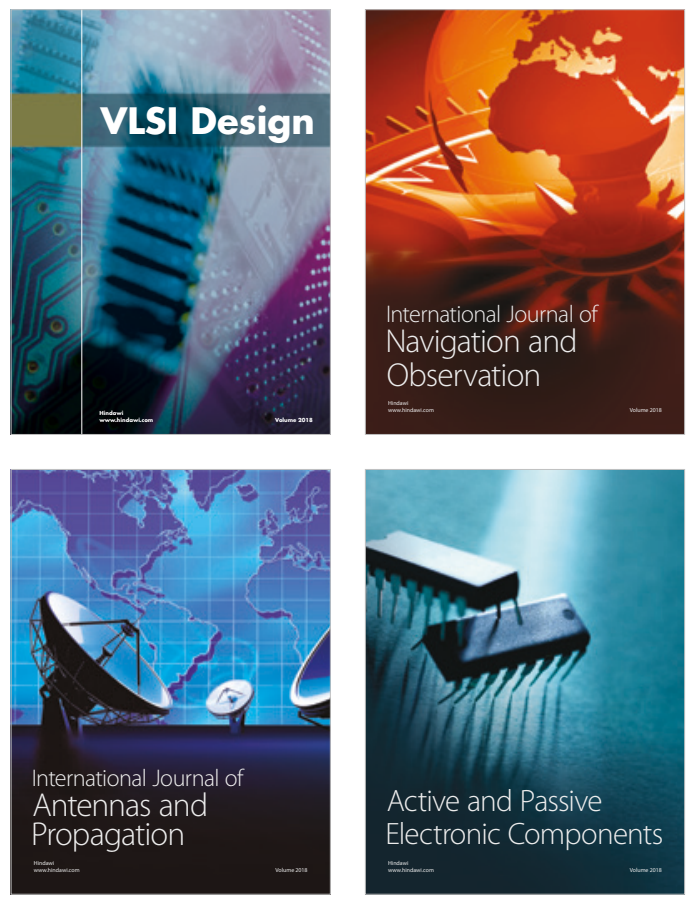
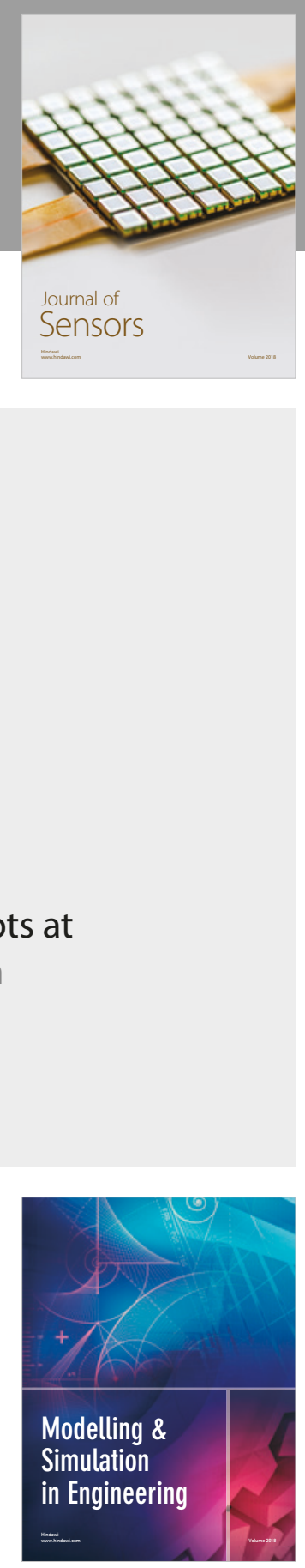

\section{Advances \\ Multimedia}
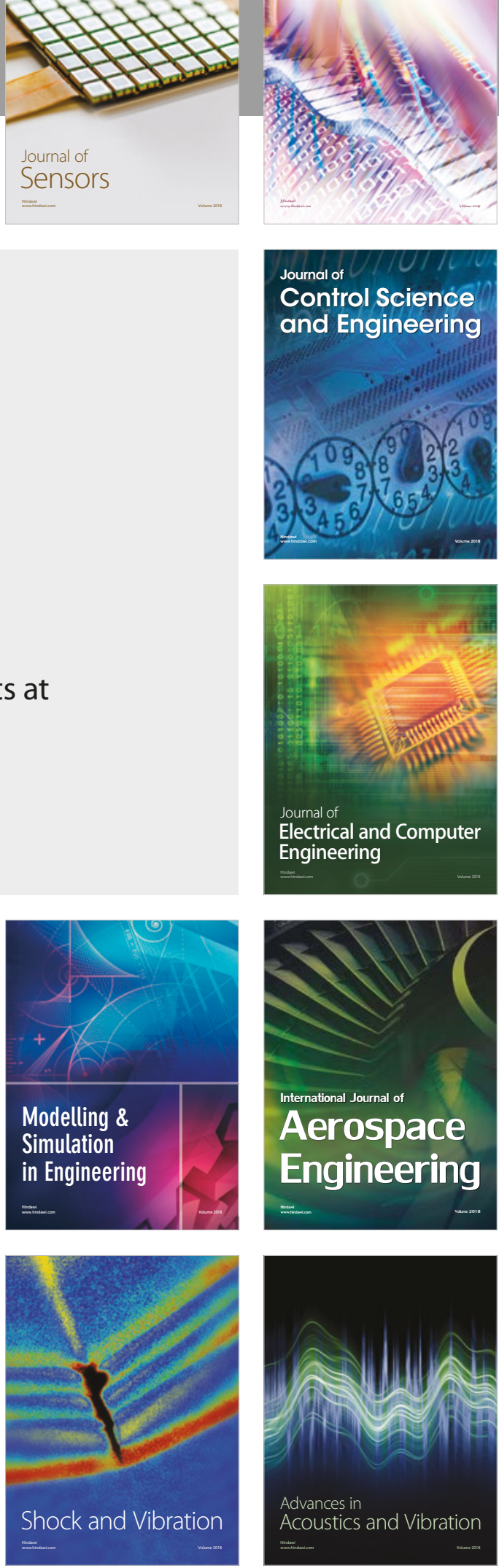